\title{
Cultivo de milho em consórcio com capins tropicais
}

\author{
Corn intercropped with tropical grasses
}

\section{Eduardo Leonel Bottega ${ }^{1 *}$, Kelen Cristina Basso ${ }^{2}$, Jonatas Thiago Piva ${ }^{2}$ e Renata Franciéli Moraes ${ }^{3}$}

\author{
Recebido em 04/04/2016 / Aceito em 30/08/2016
}

\section{RESUMO}

O consórcio de milho com capins trata-se de uma prática bastante utilizada em regiões de clima tropical. Entretanto nada se conhece sobre sua adoção em regiões de clima temperado. Este trabalho objetivou avaliar o crescimento de diferentes capins e sua influência sobre o rendimento do milho em função do sistema de semeadura adotado no cultivo em consórcio no Planalto Catarinense. O experimento foi implantado em esquema fatorial $3 \times 3$, sendo os fatores compostos por três sistemas de semeadura do capim e três cultivares de braquiárias. As médias foram avaliadas pelo teste de Tukey, a 5\% de probabilidade. O capim Urochloa ruziziensis cv. Ruziziensis apresentou maior aporte de matéria seca total. O cultivo do milho em consórcio com os capins não influenciou a produtividade da cultura, independente do sistema de semeadura e do capim utilizado.

PALAVRAS-CHAVE: Urochloa brizantha, Urochloa ruziziensis, Zea mays, produtividade, integração lavoura-pecuária.

\section{ABSTRACT}

The intercropping corn with grasses it is a widely used practice in tropical climates, but nothing is known about its adoption in temperate regions. This study aimed to evaluate the growth influence of different grasses on corn yield due to the seeding system adopted in intercropping. The experiment was established in a $3 \times 3$ factorial scheme, the factors being composed of 3 grass seeding systems and 3 cultivars of grass. The means were evaluated by Tukey test at $5 \%$ probability. The higher amount of total dry matter was obtained by Urochloa ruziziensis cv. Ruziziensis grass. The corn intercropped with the grasses did not affect the crop yield, regardless of seeding and grass used system.

KEYWORDS: Urochloa brizantha, Urochloa ruziziensis, Zea mays, yield, crop-livestock integration.

\section{INTRODUÇÃO}

O Planalto Catarinense trata-se de uma região do estado de Santa Catarina que apresenta seus campos produtivos localizados em altitudes que podem variar de 900 a 1350 metros acima do nível do mar. O clima predominante da região é o $\mathrm{Cfb}$, temperado (mesotérmico úmido e verão ameno), segundo classificação de Köeppen. A precipitação média anual varia de 1500 a $1700 \mathrm{~mm}$, com temperatura média anual de $17{ }^{\circ} \mathrm{C}$. Este clima favorece a formação de pastagens de inverno, entretanto é observado um vazio forrageiro no período do verão. Neste contexto, o estudo do cultivo de capins forrageiros em consórcio com culturas de grãos cultivadas no verão mostra-se promissor, em especial aquele realizado no sistema de plantio direto.

O plantio direto trata-se de um sistema de produção conservacionista capaz de garantir sustentabilidade de atividades agropecuárias, entretanto, os ganhos podem ser limitados pela falta de rotação de culturas. A utilização de pastagens em áreas de lavoura, por períodos de dois anos ou mais, pode contribuir para a melhoria da qualidade física dos solos (MACHADO \& ASSIS 2010). Neste contexto, o cultivo consorciado de culturas, em especial de milho com capins, têm se destacado, principalmente nas regiões tropicais, em função das condições climáticas ideais ao crescimento e desenvolvimento

\footnotetext{
${ }^{1}$ Universidade Federal de Santa Maria, Cachoeira do Sul, RS, Brasil.

${ }^{2}$ Universidade Federal de Santa Catarina, Curitibanos, SC, Brasil.

${ }^{3}$ Universidade Federal de Paraná, Curitiba, PR, Brasil.

*Autor para correspondência <bottega.elb@gmail.com>
} 
dos capins. Capins do gênero Urochloa apresentam significativo acúmulo de fitomassa a partir dos 45 dias após a semeadura, que, associado ao hábito perene (PACHECO et al. 2008), torna a espécie uma alternativa viável para a produção de forragem para pastagem ou cobertura do solo.

BORGHI et al. (2008) enfatizam que o sistema de consórcio, em especial o de milho com capins, além de fornecerem forragem após a colheita da cultura produtora de grãos, são uma excelente alternativa na formação de palha sobre o solo para semeadura da próxima safra de verão no sistema plantio direto. Estudos conduzidos por MACHADO \& ASSIS (2010) avaliaram a produção de palha e de forragem por forrageiras anuais e perenes implantadas em sucessão à cultura da soja, e observaram que as espécies Urochloa ruziziensis e Urochloa decumbens, por manterem-se em crescimento durante toda a estação seca e pela facilidade de dessecação, são boas alternativas quando se busca cobertura do solo em sistemas produtivos conservacionistas.

A adoção do sistema conservacionista envolve mudanças que podem reduzir temporariamente a produtividade das culturas (GOMEZ-REY et al. 2014), o que, em um primeiro momento, pode restringir seu emprego. Contudo, THIERFELDER \& WALL (2009) destacam como benefícios deste sistema melhorias na parte física do solo, tais como o aumento na infiltração de água, redução do escoamento superficial e da evaporação, aumento na disponibilidade de água no solo e redução dos efeitos da seca em situações de baixa pluviosidade. Neste contexto, o cultivo de forrageiras como plantas de cobertura merece destaque, pois, além dos benefícios acima citados, proporcionam melhorias no que diz respeito à parte química do solo (ciclagem de nutrientes) e também nas variáveis de ordem sanitária (MACHADO \& ASSIS 2010), como por exemplo, supressão de plantas daninhas.

A utilização do cultivo consorciado de milho e capim é consagrada em regiões tropicais do país, entretanto não existem estudos sobre a adoção do emprego de capins tropicais em consórcio com milho em regiões de clima temperado, como no caso dos campos localizados no Planalto Catarinense. Nessas regiões, a ocorrência de temperaturas elevadas e maior duração do período diário de irradiação solar são observadas no decorrer da primavera e verão, fatores determinantes para o desenvolvimento de espécies tropicais. Diante do exposto, o objetivo deste trabalho foi avaliar o crescimento e o desenvolvimento de diferentes capins em função do sistema de semeadura adotado no cultivo em consórcio com milho e também sua influência sobre os componentes de rendimento da cultura do milho no Planalto Catarinense.

\section{MATERIAL E MÉTODOS}

O experimento foi conduzido na Fazenda Agropecuária da Universidade Federal de Santa Catarina, no município de Curitibanos, SC, com coordenadas geográficas $27^{\circ} 16^{\prime} 34^{\prime \prime}$ de latitude Sul e $50^{\circ} 30^{\prime} 12^{\prime \prime}$ de longitude Oeste. Aárea apresenta altitude média em relação ao nível do mar de 1000 metros. O clima da região é classificado como temperado (mesotérmico úmido e verão ameno), segundo classificação de Köeppen. A precipitação média anual varia de 1500 a $1700 \mathrm{~mm}$, com temperatura média anual de $17{ }^{\circ} \mathrm{C}$. O solo da área experimental é classificado como Cambissolo Háplico de textura argilosa, apresentando em média $550 \mathrm{~g} \mathrm{~kg}^{-1}$ de argila (EMBRAPA 2006).

O experimento foi implantado em delineamento em blocos casualizados em esquema fatorial $3 \times 3 \mathrm{com}$ três repetições. Os fatores compostos por três sistemas de semeadura do capim (na linha, na entrelinha e a lanço) e três tipos de capim ( $U$. brizantha cv. Xaraés, U. brizantha cv. Marandu e $U$. ruziziensis cv. Ruziziensis), a semeadura foi realizada a uma profundidade de média de $0,03 \mathrm{~m}$. A combinação dos sistemas de semeadura com os capins resultou em nove tratamentos. Cada parcela experimental tinha área de $18 \mathrm{~m}^{2}$, sendo $4,5 \mathrm{~m}$ de comprimento por 4 $\mathrm{m}$ de largura, composta por cinco linhas de cultivo de milho espaçadas de $0,80 \mathrm{~m}$. A área útil, utilizada nas avaliações dos componentes de rendimento do milho foi de $9,6 \mathrm{~m}^{2}$, composta das três linhas centrais, descartando-se duas linhas da bordadura e $0,5 \mathrm{~m}$ da extremidade de cada linha. Nas avaliações dos capins na linha e na entrelinha foram utilizadas as três linhas centrais da parcela totalizando uma área útil de $9,6 \mathrm{~m}^{2}$, na semeadura a lanço também foi desconsidera a área de bordadura totalizando $12 \mathrm{~m}^{2}$.

Antes da semeadura, foram coletadas amostras de solo representativas da profundidade $0,00-0,20 \mathrm{~m}$ para caracterização da fertilidade da área. As amostras foram encaminhadas para análise e os resultados serviram como base para recomendação de adubação. Na Tabela 1 são apresentados os valores resultantes da análise de solo. 
Tabela 1 - Características químicas do solo da área experimental na camada de 0-20 cm.

Table 1 - Chemical characteristics of the experimental area soil at 0-20 cm depth.

\begin{tabular}{ccccccc}
\hline $\begin{array}{c}\mathrm{MO} \\
\mathrm{g} \mathrm{dm}^{-3}\end{array}$ & $\begin{array}{c}\mathrm{pH} \\
\mathrm{CaCl}_{2}\end{array}$ & $\begin{array}{c}\mathrm{P} \\
-------\end{array} \mathrm{mg} \mathrm{dm}^{-3}-\mathrm{K}$ & $\mathrm{Ca}$ & $\mathrm{CTC}$ & $\mathrm{V}$ \\
\hline 52,27 & 4,90 & 2,62 & 50,83 & 5,92 & 13,52 & 68,93 \\
\hline
\end{tabular}

$\mathrm{Na}$ semeadura do milho foi utilizada uma semeadora-adubadora de precisão, marca Vence Tudo $^{\circledR}$, modelo SA 11500. Para adubação de base foi utilizado $420 \mathrm{~kg} \mathrm{ha}^{-1}$ do adubo formulado NPK (00-20-20), calculada de acordo com a exigência da cultura e com base na análise de solo. Tanto a semeadura de milho quanto dos capins foi realizada no dia 10 de dezembro de 2013, sendo que os capins foram semeados manualmente a uma profundidade de $0,03 \mathrm{~m}$.

Foi utilizado o híbrido de milho AG122, depositando seis sementes por metro a uma profundidade de $0,05 \mathrm{~m}$. No estádio V4 de desenvolvimento das plantas foi realizada adubação de cobertura aplicando-se $150 \mathrm{~kg} \mathrm{ha}^{-1}$ de ureia (45\% de N) a lanço. A quantidade de sementes de capim semeada por hectare foi determinada com base no valor cultural de cada espécie. Foram utilizados $9 \mathrm{~kg} \mathrm{ha}^{-1}$ de sementes de U. ruziziensis cv. Ruziziensis, $9 \mathrm{~kg} \mathrm{ha}^{-1}$ de sementes de $U$. brizantha $\mathrm{cv}$. Marandu e $8 \mathrm{~kg} \mathrm{ha}^{-1}$ de sementes de $U$. brizantha cv. Xaraés, visando uma população de 10 a 12 plantas por $\mathrm{m}^{2}$.

A colheita do milho foi realizada de forma manual 148 dias após a semeadura, sendo recolhidas todas as espigas presentes na área útil da parcela. Para a avaliação dos componentes de rendimento foram selecionadas 10 espigas escolhidas de forma aleatória em cada parcela experimental. Os componentes de rendimento avaliados foram: comprimento da espiga, diâmetro da espiga, número de fileiras por espiga, número de grãos por fileira e peso de mil grãos. A produtividade foi determinada através da pesagem de grãos colhidos na parcela útil, ajustando-se para 14\% de umidade.

Imediatamente após a colheita do milho foram coletadas duas amostras de forragem por parcela, utilizando-se uma moldura de $0,25 \mathrm{~m}^{2}(0,5 \times 0,5$ m) e todos os perfilhos foram cortados ao nível do solo, acondicionados em sacos plásticos e levados ao laboratório para pesagem. Uma subamostra foi utilizada para separação dos componentes morfológicos (folha, colmo e material morto) e outra subamostra utilizada para determinação da porcentagem de matéria seca $(\% \mathrm{MS})$. As amostras foram levadas a estufa a $65{ }^{\circ} \mathrm{C}$ até massa constante. Os valores de massa de forragem foram convertidos para $\mathrm{kg} \mathrm{ha}^{-1}$ de MS e os componentes da forragem em porcentagem da massa de forragem. A relação folha:colmo foi obtida pela divisão dos valores médios absolutos de folhas pelos valores médios absolutos de colmos em cada parcela. Além das avaliações relacionadas a produção de massa de forragem do capim, estimou-se a densidade de perfilhos, utilizando um retângulo de $0,50 \times 0,25 \mathrm{~m}$ sendo contados todos os perfilhos contidos dentro do retângulo, posteriormente extrapolou-se os valores para $\mathrm{m}^{2}$.

A análise de variância dos dados foi realizada através do teste de F de Snedcor, a 5\% de probabilidade. Constatando-se variância significativa procedeu-se o teste de Tukey a 5\% de probabilidade, para comparação de médias. A análise de variância e o teste de médias foram realizados utilizando o programa estatístico ASSISTAT (SILVA \& AZEVEDO 2002).

\section{RESULTADOS E DISCUSSÃO}

O tipo de semeadura dos capins (linha, entrelinha, lanço) influenciou de forma significativa a massa de forragem total (MST) e a massa seca de folhas (MSF). Todos os parâmetros avaliados apresentaram diferença significativa em função do tipo de capim cultivado (U. ruziziensis cv. Ruziziensis, $U$. brizantha $\mathrm{cv}$. Marandu e U. brizantha cv. Xaraés). Não foi observada interação significativa entre os tipos de semeadura de capim adotada e o tipo de capim cultivado.

$\mathrm{Na}$ Tabela 2 é apresentado o resultado do teste de médias para as variáveis estudadas: massa de forragem total (MST), massa seca de folhas (MSF), massa seca de colmos (MSC) e massa seca de material morto (MSMM) de capins semeados na linha, entrelinha e a lanço em consórcio com o milho.

A maior produção de forragem, independente do arranjo de semeadura, foi obtida pelo capim 
Tabela 2 - Teste de médias para a massa de forragem total (MST), massa seca de folhas (MSF), massa seca de colmos (MSC) e massa seca de material morto (MSMM) de capins semeados na linha, entrelinha e a lanço em consórcio com o milho.

Table 2 - Mean test for total forage mass (MST), dry weight of leaves (MSF), dry matter of stems (MSC) and mass of dead dry matter material (MSMM) of grasses sown on the line, leading and haul intercropped with corn.

\begin{tabular}{|c|c|c|c|c|}
\hline \multirow{2}{*}{ Capim } & \multicolumn{4}{|c|}{ MST $\left(\mathrm{kg} \mathrm{ha}^{-1}\right)$} \\
\hline & Linha & Entrelinha & Lanço & Média \\
\hline Ruziziensis & $6.413,16$ & $6.286,00$ & $7.978,11$ & $6.892,42 \mathrm{~A}$ \\
\hline Marandu & $4.190,25$ & $5.327,13$ & $5.723,46$ & $5.080,28 \mathrm{~B}$ \\
\hline Xaraés & $1.550,52$ & $1.552,93$ & $2.046,68$ & $1.716,71 \mathrm{C}$ \\
\hline \multirow[t]{2}{*}{ Média } & $4.054,31 \mathrm{~b}$ & $4.388,69 \mathrm{ab}$ & $5.249,42 \mathrm{a}$ & $\mathrm{CV}^{1}(\%) 18,45$ \\
\hline & \multicolumn{4}{|c|}{$\operatorname{MSF}\left(\mathrm{kg} \mathrm{ha}^{-1}\right)$} \\
\hline Ruziziensis & $1.961,84$ & $1.864,68$ & $2.931,00$ & $2.252,50 \mathrm{~A}$ \\
\hline Marandu & $1.512,62$ & $2.069,24$ & $2.388,63$ & $1.990,16 \mathrm{~A}$ \\
\hline Xaraés & 863,55 & 904,96 & $1.085,91$ & $951,47 \mathrm{~B}$ \\
\hline \multirow[t]{2}{*}{ Média } & $1.446,00 \mathrm{~b}$ & $1.612,96 \mathrm{~b}$ & $2.135,17 \mathrm{a}$ & $\mathrm{CV}(\%) 24,38$ \\
\hline & \multicolumn{4}{|c|}{ MSC $\left(\mathrm{kg} \mathrm{ha}^{-1}\right)$} \\
\hline Ruziziensis & $4.281,18$ & $4.274,83$ & $4.949,91$ & $4.501,97 \mathrm{~A}$ \\
\hline Marandu & $2.604,18$ & $3.189,68$ & $3.243,37$ & $3.012,41 \mathrm{~B}$ \\
\hline Xaraés & 677,90 & 630,63 & 960,77 & $756,43 \mathrm{C}$ \\
\hline \multirow[t]{2}{*}{ Média } & $2.521,09$ & $2.698,38$ & $3.051,35$ & $\mathrm{CV}(\%) 19,51$ \\
\hline & \multicolumn{4}{|c|}{$\operatorname{MSMM}\left(\mathrm{kg} \mathrm{ha}^{-1}\right)$} \\
\hline Ruziziensis & 170,15 & 146,49 & 97,21 & $137,95 \mathrm{~A}$ \\
\hline Marandu & 73,45 & 68,20 & 91,46 & $77,70 \mathrm{~A}$ \\
\hline Xaraés & 9,07 & 17,34 & 0,00 & $8,80 \mathrm{~B}$ \\
\hline Média & 84,22 & 77,34 & 62,89 & $\mathrm{CV}(\%) 70,81$ \\
\hline
\end{tabular}

Médias seguidas pela mesma letra, maiúscula na coluna e minúscula na linha, não diferem estatisticamente entre si pelo Teste de Tukey $(\mathrm{p}<0,05)$. ${ }^{1}$ Coeficiente de variação.

Ruziziensis (6.892 $\left.\mathrm{kg} \mathrm{ha}^{-1}\right)$, conforme apresentado na Tabela 3. Quando a semeadura foi realizada na linha, independente do capim obteve-se menor produção total de forragem $\left(4.054,31 \mathrm{~kg} \mathrm{ha}^{-1}\right)$. Não houve interação significativa entre o tipo de capim e o sistema de semeadura utilizado.

PARIZ et al. (2011) avaliaram a produção de forragem dos capins Ruziziensis e Marandu, semeados a lanço e na linha em consórcio com o milho, e observaram maior produção de massa do capim Ruziziensis quando semeado a lanço, diferindo em $1.800 \mathrm{~kg} \mathrm{ha}^{-1}$ em relação a semeadura na linha. A produção de forragem do capim Marandu não apresentou diferença significativa em função do sistema de semeadura adotado.

Os capins Ruziziensis e Marandu apresentaram as maiores médias de produção de folhas $(2.252,50$ e $1.990,16 \mathrm{~kg} \mathrm{ha}^{-1}$, respectivamente) e de material morto (137,95 e 77,70 $\mathrm{kg} \mathrm{ha}^{-1}$, respectivamente), independente do tipo de semeadura empregada (Tabela 2). FREITAS et al. (2005), PARIZ et al. (2009) e PARIZ et al. (2011) relatam que estes capins apresentam tolerância parcial ao sombreamento e a competição com a cultura acompanhante, não afetando de forma acentuada a produção.

A massa de colmos e material morto observada deve-se, principalmente, ao sombreamento dos estratos mais basais devido à interceptação luminosa 
Tabela 3 - Teste de médias para o número de perfilhos $\left(\mathrm{m}^{2}\right)$, porcentagem de folhas $(\% \mathrm{~F})$, porcentagem de colmos $(\% \mathrm{C})$, porcentagem de material morto $(\% \mathrm{MM})$ e relação folha colmo (RFC) de diferentes capins semeados na linha, entrelinha e a lanço em consórcio com o milho.

Table 3 - Mean test for the number of tillers $\left(\mathrm{m}^{2}\right)$, percentage of leaves $(\% \mathrm{~F}$, percentage of stems $(\% \mathrm{C})$, percentage of dead material (\%MM) and leaf stems relationship (LSR) of different grasses sown on the line, leading and haul in consortium with corn.

\begin{tabular}{|c|c|c|c|c|}
\hline \multirow{2}{*}{ Capim } & \multicolumn{4}{|c|}{ PERFILHOS } \\
\hline & Linha & Entrelinha & Lanço & Média \\
\hline Ruziziensis & 228,7 & 189,0 & 295,0 & $237,6 \mathrm{~A}$ \\
\hline Marandu & 148,7 & 192,0 & 253,0 & $197,9 \mathrm{~A}$ \\
\hline Xaraés & 60,0 & 57,0 & 78,0 & $65,0 \mathrm{~B}$ \\
\hline \multirow[t]{2}{*}{ Média } & $145,8 \mathrm{~b}$ & $146,0 \mathrm{~b}$ & $208,7 \mathrm{a}$ & $\mathrm{CV}^{1}(\%) 21,87$ \\
\hline & \multicolumn{4}{|c|}{$\% \mathrm{~F}$} \\
\hline Ruziziensis & 30,37 & 29,65 & 37,00 & $32,34 \mathrm{C}$ \\
\hline Marandu & 37,21 & 38,93 & 40,64 & $38,93 \mathrm{~B}$ \\
\hline Xaraés & 55,16 & 57,72 & 53,83 & $55,57 \mathrm{~A}$ \\
\hline \multirow[t]{2}{*}{ Média } & 40,91 & 42,10 & 43,82 & $\mathrm{CV}(\%) 9,29$ \\
\hline & \multicolumn{4}{|c|}{$\% \mathrm{C}$} \\
\hline Ruziziensis & 66,69 & 68,02 & 61,77 & $65,49 \mathrm{~A}$ \\
\hline Marandu & 61,13 & 59,81 & 57,81 & $59,54 \mathrm{~B}$ \\
\hline Xaraés & 44,06 & 41,48 & 46,17 & $43,91 \mathrm{C}$ \\
\hline \multirow[t]{2}{*}{ Média } & 57,30 & 56,44 & 55,21 & $\mathrm{CV}(\%) 6,40$ \\
\hline & \multicolumn{4}{|c|}{$\% \mathrm{MM}$} \\
\hline Ruziziensis & 2,94 & 2,31 & 1,23 & $2,19 \mathrm{~A}$ \\
\hline Marandu & 1,64 & 1,26 & 1,66 & $1,52 \mathrm{AB}$ \\
\hline Xaraés & 0,74 & 0,80 & 0,00 & $0,52 \mathrm{C}$ \\
\hline \multirow[t]{2}{*}{ Média } & 1,77 & 1,46 & 0,96 & $\mathrm{CV}(\%) 79,36$ \\
\hline & \multicolumn{4}{|c|}{ RFC } \\
\hline Ruziziensis & 0,46 & 0,43 & 0,60 & $0,50 \mathrm{C}$ \\
\hline Marandu & 0,62 & 0,65 & 0,72 & $0,67 \mathrm{~B}$ \\
\hline Xaraés & 1,20 & 1,40 & 1,17 & $1,27 \mathrm{~A}$ \\
\hline Média & 0,77 & 0,82 & 0,83 & $\mathrm{CV}(\%) 14,66$ \\
\hline
\end{tabular}

Médias seguidas pela mesma letra, maiúscula na coluna e minúscula na linha, não diferem estatisticamente entre si pelo Teste de Tukey $(\mathrm{p}<0,05)$. ${ }^{1}$ Coeficiente de variação.

exercida pelas plantas. Gramíneas em situação de sombreamento, na busca por luz, aumentam o alongamento de colmos como forma de expor as folhas mais novas na parte superior do dossel, onde existe maior incidência luminosa, porém, este mecanismo faz com que os estratos basais fiquem ainda mais sombreados aumentando a senescência (LEMAIRE 2001, CARNEVALLI et al. 2006 e SBRISSIA \& SILVA 2008). É provável que o maior sombreamento na base das plantas, tenha inibido o perfilhamento, haja vista que a redução na intensidade luminosa é um dos fatores de ambiente que reduz o perfilhamento em gramíneas.

$\mathrm{Na}$ semeadura a lanço houve maior produção de folhas $\left(2.135,17 \mathrm{~kg} \mathrm{ha}^{-1}\right)$. Neste tipo de semeadura ocorre melhor distribuição (arranjo) das plantas na área mesmo estando na mesma densidade de plantas (PARIZ et al. 2011), tal fato permite a disposição de perfilhos mais ou menos próximos as plantas de milho, ou seja, em locais com maior ou menor interceptação luminosa. Nos locais onde ocorre maior radiação solar na base do dossel, a luz incidente ativa as gemas basais, mais perfilhos são formados e o perfilhamento é a principal característica para o aumento na produção de folhas (DAVIES 1974).

A maior produção de forragem do capim Ruziziensis pode estar associada a maior massa de colmos observada neste cultivar $\left(4.501,97 \mathrm{~kg} \mathrm{ha}^{-1}\right.$; Tabela 2), sendo os colmos um componente que confere maior peso a massa total de forragem, porém, 
com valores nutricionais muito abaixo do conteúdo das folhas. Além disso, não foi aplicado nenhuma subdosagem de herbicida nicosulfuron para retardar o crescimento das gramíneas.

A menor produção de forragem total, folhas, colmo e material morto foram observados para o capim Xaraés. Este fato pode ser explicado pela característica deste capim em apresentar germinação e crescimento mais lentos quando comparado com os outros capins estudados. Os resultados obtidos foram menores que os relatados em outros trabalhos que também avaliaram o consórcio de milho com a $U$. brizantha cv. Xaraés (COSTA et al. 2012) realizados em regiões de clima tropical. É possível que o clima ameno, com noites mais frias, somado a competição das plantas em consórcio tenha interferido no potencial de crescimento desta cultivar.

COSTA et al. (2012) avaliaram a produtividade do milho em consórcio com os capins Xaraés e Ruziziensis e doses de nitrogênio, os resultados de massa de forragem total obtidos foram de 5.000 e $6.000 \mathrm{~kg} \mathrm{ha}^{-1}$ de matéria seca, não sendo observada diferença entre as cultivares. Os autores ainda relatam que o consórcio garante forragem para o fornecimento à alimentação animal, após a colheita da cultura do milho, a pastagem estará estabelecida para utilização do outono à primavera.

Os resultados do teste de médias para número de perfilhos $\mathrm{m}^{-2}$, porcentagem de folhas $(\% \mathrm{~F})$, porcentagem de colmos $(\% \mathrm{C})$, porcentagem de material morto (\%MM) e relação folha colmo (RFC) dos diferentes capins semeados na linha, entrelinha e a lanço em consórcio com o milho, são apresentados na Tabela 3.

Os capins Ruziziensis e Marandu apresentaram o maior densidade de perfilhos (237,6 e 197,9 perfilhos $\mathrm{m}^{-2}$, respectivamente) sendo esses também os capins que foram mais produtivos. A semeadura a lanço foi a que proporcionou maior número de perfilhos, sendo contabilizados, em média, 208,7 perfilhos $\mathrm{m}^{-2}$ (Tabela 3). A densidade populacional de perfilhos é uma característica importante, pois a produção de matéria seca de uma pastagem é diretamente relacionada ao número de perfilhos, na semeadura a lanço, pode ter ocorrido maior distribuição das plantas na área o que permitiu que maior quantidade de luz chegasse a base do dossel, o que pode aumentar o perfilhamento devido a ativação das gemas basais.

A porcentagem de folhas foi maior no capim Xaraés $(55,57 \%)$ e não variou com os arranjos de semeadura (Tabela 4). Esta é uma variável importante quando se almeja o retorno mais rápido de matéria orgânica para o solo, devido a menor relação C:N que a fração colmos, como também para a formação do pasto devido a maior capacidade fotossintética e valor nutritivo. O capim Xaraés também apresentou a maior relação folha:colmo $(1,27)$, apesar de ter sido observada menor massa de forragem total, a maior parte desta foi composta por folhas, característica desejável quando o objetivo é a formação de pastagem.

Menores valores de $\% \mathrm{~F}(32,24 \%)$ e RFC $(0,50)$ foram observados no capim Ruziziensis, e maior $\% \mathrm{C}$ $(65,49 \%)$. Esta cultivar possui colmos geniculados e seu hábito de crescimento é mais prostrado e, segundo COSTA et al. (2012) ocupa rapidamente o solo. SEREIA et al. (2012) avaliaram os capins Ruziziensis e Marandu e observaram que o maior índice de colmos e produtividade de massa também foi observado no capim Ruziziensis.

O capim Marandu apresentou valores de produção de massa de forragem, folhas e colmos intermediários, porém com massa seca de folhas semelhante ao capim Ruziziensis, sem, no entanto, apresentar igual porcentagem de colmos. DIAS FILHO (2002), relata que a $U$. brizantha sombreada reduz sua capacidade fotossintética, porém apresenta determinada plasticidade fenotípica e tolerância em resposta ao sombreamento, o que permite o crescimento e a viabilidade do consórcio.

Os componentes da produção e a produtividade do milho não foram afetados pelo consórcio com os capins testados. (Tabela 4). De acordo com a CONAB (2014), a produtividade média de milho obtida na maioria dos tratamentos foi próxima a média estadual (7.334 $\left.\mathrm{kg} \mathrm{ha}^{-1}\right)$ e superior a média nacional (4.755 $\left.\mathrm{kg} \mathrm{ha}^{-1}\right)$. Estes resultados indicam que o cultivo em consórcio de milho com capins tropicais mostra-se promissor, uma vez que, além da produção de grãos, o agricultor pode contar com o aporte de forragem no período em que esta é escassa na região.

GOETTEN (2014) estudando o efeito da adubação nitrogenada na cultura do milho em experimento conduzido no mesmo talhão e época em que o presente estudo foi realizado constatou produtividade média de $6.861,58 \mathrm{~kg} \mathrm{ha}^{-1}$ para tratamento com aplicação de $40 \mathrm{~kg}$ de $\mathrm{N}$ por hectare $(88,8 \mathrm{~kg}$ de ureia por hectare). Neste estudo, aplicouse $150 \mathrm{~kg} \mathrm{ha}^{-1}$ de ureia $(45 \%$ de $\mathrm{N})$, que equivale a $67,5 \mathrm{~kg}$ de $\mathrm{N}$ por hectare, a produtividade obtida foi próxima à observada por GOETTEN (2014), embora 
Tabela 4 - Análise de variância para o comprimento de espiga (CE), diâmetro de espiga (DE), número de fileiras (NF), número de grãos por fileira (NGF), peso de mil grãos (PMG) e produtividade (PRD) de milho cultivado com diferentes capins na linha, entrelinha e a lanço.

Table 4 - Variance analysis for the length of the cob (CE), ear diameter (DE), number of ranks (NF), number of kernels per row (NGF), thousand grain weight (PMG) and corn yield (PRD) grown with different grasses on the line, and leading the haul.

\begin{tabular}{ccccccc}
\hline Tratamentos $^{1}$ & CE $(\mathrm{cm})$ & DE $(\mathrm{cm})$ & NF & NGF & PMG $(\mathrm{kg})$ & PRD $\left(\mathrm{kg} \mathrm{ha}^{-1}\right)$ \\
\hline RLI & 12,64 & 4,65 & 16,06 & 27,36 & 0,245 & $6.663,06$ \\
REL & 12,74 & 4,69 & 15,66 & 27,03 & 0,252 & $6.213,39$ \\
RLA & 12,53 & 4,55 & 15,60 & 27,40 & 0,234 & $6.101,39$ \\
MLI & 13,65 & 4,77 & 16,06 & 29,90 & 0,261 & $7.361,69$ \\
MEL & 13,50 & 4,71 & 16,13 & 30,26 & 0,245 & $6.843,16$ \\
MLA & 13,15 & 4,73 & 15,80 & 28,53 & 0,252 & $6.550,35$ \\
XLI & 13,28 & 4,76 & 16,20 & 29,86 & 0,258 & $7.204,13$ \\
XEL & 12,83 & 4,71 & 16,73 & 28,10 & 0,229 & $6.431,33$ \\
XLA & 13,88 & 4,86 & 16,26 & 30,73 & 0,265 & $7.571,53$ \\
\hline
\end{tabular}

\begin{tabular}{lcccccc}
\hline & \multicolumn{5}{c}{ Teste F de Snedcor } \\
\hline Semeaduras (S) & $0,177^{\text {ns }}$ & $0,269^{\text {ns }}$ & $0,653^{\text {ns }}$ & $0,118^{\text {ns }}$ & $0,911^{\text {ns }}$ & $0,485^{\text {ns }}$ \\
Capins (C) & $0,428^{\text {ns }}$ & $1,119^{\text {ns }}$ & $2,836^{\text {ns }}$ & $0,508^{\text {ns }}$ & $0,531^{\text {ns }}$ & $0,557^{\text {ns }}$ \\
S x C & $0,152^{\text {ns }}$ & $0,248^{\text {ns }}$ & $0,526^{\text {ns }}$ & $0,135^{\text {ns }}$ & $0,706^{\text {ns }}$ & $0,165^{\text {ns }}$ \\
\hline CV $^{2}(\%)$ & 23,56 & 6,32 & 3,50 & 24,44 & 16,35 & 40,70 \\
W & $0,629^{\text {ns }}$ & $0,575^{\text {ns }}$ & $0,058^{\text {ns }}$ & $0,372^{\text {ns }}$ & $0,762^{\text {ns }}$ & $0,44^{\text {ns }}$ \\
\hline
\end{tabular}

${ }^{1}$ RLI: Urochloa ruziziensis cv. Ruziziensis semeada na linha de plantio do milho; REL: U. ruziziensis cv. Ruziziensis semeada na entrelinha de plantio do milho; RLA: U. ruziziensis cv. Ruziziensis semeada a lanço; MLI: $U$. brizantha cv. Marandu semeada na linha de plantio do milho; MEL: U. brizantha cv. Marandu semeada na entrelinha de plantio do milho; MLA: U. brizantha cv. Marandu semeada a lanço; XLI: $U$. brizantha cv. Xaraés semeada na linha de plantio do milho; XEL: U. brizantha cv. Xaraés semeada na entrelinha de plantio do milho; XLA: $U$. brizantha $\mathrm{cv}$. Xaraés semeada a lanço. ${ }^{\text {ns }}$ não significativo pelo Teste de Tukey $(\mathrm{p}<0,05)$. W: Teste de normalidade de Shapiro-Wilks: ${ }^{\text {ns }}$ distribuição normal $(\mathrm{p}<0,05)$. ${ }^{2}$ Coeficiente de variação.

a dose de $\mathrm{N}$ utilizada seja maior. Este fato pode ser explicado pela competição entre o capim com o milho por este nutriente. Entretanto a produtividade de milho foi acima da média nacional e, além do milho, a mesma área forneceu um bom aporte de forragem, que poderia ser utilizado na alimentação animal, em uma época do ano onde a disponibilidade de pasto é crítica para a região. Isso demostra o potencial do cultivo consorciado entre milho e capins tropicais no Planalto Catarinense.

O peso de mil grãos também não diferiu significativamente em estudo realizado por RICHART et al. (2010) no estado do Paraná. O número de fileiras por espiga (NF) não foi influenciado pelos tratamentos estudados. De acordo com FREITAS et al. (2013) o número de fileiras de grãos por espiga tem grande controle genético e, por isto, normalmente é pouco influenciado por fatores externos.

O comprimento de espiga (CE) e o diâmetro de espiga (DE) não apresentaram diferenças significativas corroborando com resultados encontrados por RICHART et al. (2010). PARIZ et al. (2011) observaram em seu estudo que o capim Ruziziensis, quando semeado na linha e a lanço, apresentou variação no número de grão por fileiras. Segundo o autor esta variação resulta em perda na produtividade. Resultado divergente foi observado no presente estudo, onde o sistema de semeadura do capim não influenciou significativamente o número de grãos por fileira. 
De acordo com os resultados obtidos, o cultivo de milho em consórcio com os capins avaliados mostrou-se alternativa viável, pois, não influenciou de forma significativa sobre a produtividade da cultura, fornecendo, após a colheita, um aporte forrageiro na época de maior déficit. Recomenda-se a repetição deste estudo em outros locais que apresentam clima temperado, buscando com isso um melhor entendimento da dinâmica do sistema de consórcio entre milho e capins tropicais.

\section{CONCLUSÃO}

Independente do arranjo de semeadura o capim Ruziziensis apresentou maior produção de forragem.

Os capins braquiária e os arranjos de semeadura utilizados não influenciaram na produtividade do milho.

\section{REFERÊNCIAS}

BORGHI E et al. 2008. Influência da distribuição espacial do milho e da Brachiaria brizantha consorciados sobre a população de plantas daninhas em sistema plantio direto na palha. Planta Daninha 26: 559-568.

CARNEVALLI RA et al. 2006. Herbage production and grazing losses in Panicum maximum cv. Mombaça under four grazing managements. Tropical Grasslands 40: 165176.

CONAB. 2014. Companhia Nacional de Abastecimento. $8^{\circ}$ levantamento de safra. Disponível em: $<$ http://www.conab. gov.br/OlalaCMS/uploads/arquivos/14_05_08_10_11_00_ boletim_graos_maio_2014.pdf >. Acesso em: 05 ago. 2014. COSTA NR et al. 2012. Adubação nitrogenada no consórcio de milho com duas espécies de braquiária em sistema plantio direto. Pesquisa Agropecuária Brasileira 47: 10381047.

DAVIES A. 1974. Leaf tissue remaining after cutting and regrowth in perennial ryegrass. Journal of Agricultural Science 82: 165-172.

DIAS FILHO MB. 2002. Photosynthetic light response of $\mathrm{C}_{4}$ grasses Brachiaria brizantha and Brachiaria humidicola under shade. Scientia Agricola 59: 65-68.

EMBRAPA - Empresa Brasileira de Pesquisa Agropecuária. 2006. Sistema Brasileiro de Classificação de Solos. Rio de Janeiro. 412p.

FREITAS FCL et al. 2005. Formação de pastagem via consórcio de Brachiaria brizantha com o milho para silagem no sistema de plantio direto. Planta Daninha 23: 49-58.

FREITAS RJ et al. 2013. População de plantas de milho consorciado com Urochloa ruziziensis. Pesquisa Agropecuária Tropical 43: 79-87.
GOETTEN M. 2014. Adubação nitrogenada no milho em sistema de integração lavoura-pecuária. Trabalho de Conclusão de Curso (Graduação em Agronomia). Curitibanos: UFSC. $24 f$.

GOMEZ-REY MX et al. 2014. Soil P and cation availability and crop uptake in a forage rotation under conventional and reduced tillage. Soil Use and Management 30: 1-9.

LEMAIRE G. 2001. Ecophisiology of grasslands: dynamic aspects of forage plant populations in grazed swards. In: GOMIDE JA et al. (Eds.). 19 International Grassland Congress. Proceedings... São Pedro: FEALQ. p. 29-37.

MACHADO LAZ \& ASSIS PGA. 2010. Produção de palha e forragem em sucessão à soja. Pesquisa Agropecuária Brasileira 45: 415-422.

PACHECO LP et al. 2008. Desempenho de plantas de cobertura em sobressemeadura na cultura da soja. Pesquisa Agropecuária Brasileira 43: 815-823.

PARIZ CM et al. 2009. Desempenhos técnicos e econômicos da consorciação de milho com forrageiras dos gêneros Panicum e Brachiaria em sistema de integração lavoura-pecuária. Pesquisa Agropecuária Tropical 39: 360370.

PARIZ CM et al. 2011. Produtividade de grãos de milho e massa seca de braquiárias em consórcio no sistema de integração lavoura-pecuária. Ciência Rural 41: 875-882.

RICHART A et al. 2010. Desempenho do milho safrinha e da Brachiaria ruziziensis cv. Comum em consórcio. Revista Brasileira de Ciências Agrárias 5: 497-502.

SBRISSIA AF \& SILVA SC. 2008. Compensação tamanho/ densidade populacional de perfilhos em pastos de capimmarandu. Revista Brasileira de Zootecnia 37: 35-47.

SEREIA RC et al. 2012. Crescimento de Brachiaria spp. e milho safrinha em cultivo consorciado. Agrarian 5: 349355.

SILVA FAS \& AZEVEDO CAV. 2002. Versão do programa computacional Assistat para o sistema operacional Windows. Revista Brasileira de Produtos Agroindustriais 4: 71-78.

THIERFELDER C \& WALL PC. 2009. Effects of conservation agriculture techniques on infiltration and soil water content in Zambia and Zimbabwe. Soil \& Tillage Research 105: 217-227. 